\title{
Kepuasan Konsumen dan Intensi Pembelian Ulang Produk Kue Artis pada Mahasiswa
}

\author{
Nindita Devirahma Hutami, Aditya Nanda Priyatama, Pratista Arya Satwika \\ Program Studi Psikologi, Fakultas Kedokteran, Universitas Sebelas Maret, Surakarta
}

\begin{abstract}
Abstrak. Inovasi produk dalam bidang kuliner terus berkembang di Indonesia. Salah satu bentuk inovasi tersebut adalah kue artis. Penelitian ini bertujuan untuk mengetahui hubungan antara kepuasan konsumen dan intensi pembelian ulang produk kue artis pada mahasiswa di salah satu universitas di Surakarta. Penelitian ini menggunakan purposive sampling dengan sampel sebanyak 450 mahasiswa yang memiliki dua kriteria, yaitu mahasiswa S1 aktif di salah satu universitas di Surakarta serta pernah membeli produk kue artis secara langsung di gerainya. Berdasarkan hasil analisis diketahui bahwa hipotesis diterima, sehingga terbukti ada hubungan yang signifikan antara kepuasan konsumen dan intensi pembelian ulang $(p<.05)$. Hasil penelitian menunjukkan bahwa semakin tinggi tingkat kepuasan konsumen, maka semakin tinggi pula niat konsumen untuk membeli ulang produk kue artis.
\end{abstract}

Kata Kunci: kepuasan konsumen, intensi pembelian ulang

\section{Customer Satisfaction and Repurchase Intention of Celebrity's Cake Product among Students}

\begin{abstract}
Product innovation in culinary business always to grow in Indonesia. The celebrity's cake product as an example of product innovation in culinary business. This study aims to determine the relation between customer satisfactions and repurchase intention of celebrity's cake product on the students in one of universities in Surakarta. This study uses purposive sampling technique with 450 samples which has two criterions; undergraduate student in one of universities in Surakarta and has experienced of buying celebrity's cake product by visiting the outlet. The hypothesis was accepted according to the result of the analysis, so that there was a significant relationship between customer satisfaction and repurchase intention $(p<.05)$. The results showed that the higher the customer satisfaction, the higher the repurchase intention of celebrity's cake product.
\end{abstract}

Keywords: customer satisfaction, repurchase intention

Korespondensi: Nindita Devirahma Hutami. Email: ddevirahma@gmail.com 
Inovasi produk dalam bidang kuliner terus berkembang di Indonesia. Salah satu bentuk inovasi tersebut adalah kue artis. Kue artis merupakan suatu produk makanan yang tidak termasuk jenis makanan khas dari suatu daerah namun berlabel sebagai oleh-oleh dari daerah tersebut. Kekhasan lain dari kue artis adalah menggunakan selebriti sebagai pendukungnya. Bisnis kue artis ini dipelopori oleh aktor Indonesia, yaitu Teuku Wisnu yang membuka gerai bernama Malang Strudel pada
24 Desember 2014. Hingga tahun 2018, terdapat lebih dari 75 kue artis yang membuka gerai di berbagai daerah di Indonesia (Alga, 2019) .

Kota Surakarta juga menjadi salah satu incaran para artis untuk membuka gerai kue artis. Hal ini tidak lain karena kota Surakarta memiliki potensi bisnis yang besar, termasuk bisnis kuliner (Saeroji \& Wijaya, 2017). Sampai tahun 2018, terdapat empat gerai kue artis yang berada di kota Surakarta seperti yang terdapat pada Tabel 1.

\section{Tabel 1}

Daftar Kue Artis di Kota Surakarta Tahun 2018

\begin{tabular}{ccc}
\hline No & Nama produk & Pemilik \\
\hline 1 & Solo Pluffy & Jessica Mila \\
2 & Solo Prabu & Febri Kempling \\
3 & Vallens Cake & Via Vallen \\
4 & Solovely & Desta Mahendra \\
\hline
\end{tabular}

Catatan. Sumber: travel.tribunnews.com, 2018

Hadirnya kue artis yang berlabel sebagai oleh-oleh dari kota Surakarta menambah variasi oleh-oleh di kota ini selain kuliner khas yang sudah ada. Contoh makanan khas kota Surakarta adalah kue Mandarijn dan kue Serabi Solo (Saeroji \& Wijaya, 2017). Kedua makanan tersebut sudah menjadi kuliner khas dan menjadi pilihan oleh-oleh makanan dari kota Surakarta. Guerrero (Pieniak et al., 2009) mendefinisikan kuliner khas sebagai makanan yang sering dikonsumsi oleh sekelompok masyarakat yang dihidangkan pada waktu tertentu, diwariskan dari satu generasi ke generasi berikutnya, diciptakan dengan resep turun temurun, dibuat tanpa atau dengan sedikit rekayasa, dan memiliki karakteristik khusus yang membedakannya dengan kuliner daerah lain.

Data dari Badan Ekonomi Kreatif (Bekraf) menunjukkan bahwa bidang kuliner paling banyak berkontribusi dalam Produk Domestik Bruto Ekonomi Kreatif, yaitu sebanyak 41.69\% (BEKRAF, 2017). Hal tersebut mendorong para pengusaha untuk menetapkan strategi pemasaran yang tepat agar produknya dapat bertahan dan bersaing dengan kompetitornya. Abdullah dan Tantri (2012) menyatakan bahwa tugas pengusaha tidak berakhir sampai suatu produk dibeli, namun harus dilanjutkan sampai tahap setelah pembelian. Pada tahap setelah pembelian, konsumen diharapkan untuk menggunakan 
atau mengonsumsi kembali produk yang sama. Hal ini menunjukkan betapa pentingnya menetapkan strategi pemasaran yang tepat agar konsumen kembali membeli ulang produkyang dibuat oleh produsen.

Intensi pembelian ulang (repurchase intention) merupakan niat konsumen yang muncul setelah melakukan pembelian. Niat tersebut muncul atas dasar kepuasan yang diperoleh dari produk yang dibeli, kemudian diikuti dengan kecenderungan konsumen untuk mengatakan hal-hal baik terkait dengan produk tersebut (Kotler \& Keller, 2012). Intensi pembelian ulang direfleksikan oleh konsumen dengan rencana pembelian suatu produk yang sama di masa yang akan datang (Rahayu et al., 2016). Pengalaman konsumen dengan perusahaan dan produk yang ditawarkan akan memengaruhi respon perilaku konsumen, yaitu perilaku membeli ulang dan merekomendasikan produk kepada kerabat dan rekan-rekannya (Lunnette \& Andreani, 2017). Jika konsumen menilai sebuah perusahaan mampu memberikan pelayanan yang inovatif, fleksibel, berorientasi pada dokumen, menyenangkan, dan dapat dipercaya, maka intensi pembelian ulang konsumen akan meningkat (Nikbin et al., 2011). Prastyaningsih et al (2014) menyatakan bahwa jika konsumen mendapatkan pengalaman positif dari suatu produk, maka konsumen akan terpuaskan, yang pada akhirnya akan mendorong konsumen untuk melakukan pembelian berulang. Oleh karena itu, penting bagi pengusaha untuk mengetahui faktor-faktor yang memengaruhi intensi pembelian ulang konsumen.

Sebuah penelitian yang dilakukan oleh Altintzoglou et al. (2016) menemukan bahwa faktor utama yang memengaruhi wisatawan dalam melakukan intensi pembelian ulang panganan oleh-oleh yaitu kualitas, rasa, juga keautentikan dan keaslian makanan tersebut Hasil penelitian Fungai (2017) menemukan faktorfaktor yang memengaruhi intensi pembelian ulang pada industri makanan cepat saji, di antaranya adalah: (a) promosi, (b) kualitas pelayanan, (c) harapan konsumen, (d) merek, (e) lingkungan fisik, (f) harga, dan (g) rasa produk. Sebuah penelitian yang dilakukan oleh Tudoran dan Olsen (2016) mengenai perilaku konsumen pada produk makanan baru di Spanyol mengungkapkan bahwa intensi pembelian ulang dipengaruhi oleh tingkat kepuasan konsumen (customer satisfaction). Konsumen harus berada pada tingkat kepuasan "sangat puas" agar memiliki intensi pembelian ulang yang lebih tinggi dan akan memiliki kemungkinan yang lebih besar untuk melakukan pembelian berulang pada produk makanan baru. Hal ini disebabkan karena makanan termasuk dalam kategori produk hedonis, yaitu produk yang dikonsumsi dengan tujuan kesenangan dan kenikmatan, sehingga diperlukan adanya dominansi pengalaman positif bagi konsumen agar mencapai tingkat kepuasan "sangat puas", sehingga muncul intensi pembelian ulang yang tinggi (Tudoran \& Olsen, 2016). 
Kepuasan konsumen tercapai jika suatu produk memenuhi harapan konsumen. Kepuasan konsumen menurut Hoyer dan Maclnnis (2010) adalah perasaan subjektif dan evaluasi objektif yang menjelaskan bahwa keputusan yang diambil oleh konsumen sudah memenuhi kebutuhan atau tujuannya. Setelah konsumen mengonsumsi suatu produk, maka konsumen dapat melakukan evaluasi hasil dari keputusan pembelian yang dilakukannya. Jika evaluasi tersebut positif, di mana kebutuhan dan tujuan konsumen terpenuhi, maka kepuasan konsumen tercapai. McQuitty et al. (2000) menyatakan bahwa kepuasan konsumen merupakan hal yang penting bagi perusahaan karena berkaitan dengan keuntungan perusahaan dan probabilitas pembelian ulang (Widjaja, 2009). Perasaan kepuasan atau ketidakpuasan yang dirasakan konsumen akan memengaruhi konsumen untuk melakukan pembelian ulang atau tidak, dan penyampaian hal-hal positif atau negatif yang terkait dengan produk kepada orang lain (Abdullah \& Tantri, 2012). Hal tersebut membuat pengusaha harus memperhatikan hal-hal yang dapat memengaruhi kepuasan konsumen.

Beberapa hal yang memengaruhi kepuasan konsumen dalam membeli produk makanan adalah merek dan kemasan, keunikan makanan, kualitas makanan, keaslian, rasa makanan, dan nilai makanan (Suhartanto et al, 2018). Adapun menurut penelitian yang dilakukan oleh Setiono et al. (2016), kepuasan konsumen dipengaruhi oleh: (1) Proses penyajian dan pembayaran yang cepat; (2) Keterjangkauan harga dan kesesuaian harga dengan kualitas dan kuantitas produk; (3) Lokasi yang mudah diakses konsumen; dan (4) Penampilan pelayan gerai saat melayani konsumen. Jika produk yang disajikan, pelayanan yang didapatkan, serta suasana tempat dinilai sepadan dengan pengorbanan yang dilakukan oleh konsumen, maka konsumen akan puas (Junaidi, 2015). Produk makanan yang berkualitas dan lezat akan memengaruhi kepuasan konsumen Setiono et al. (2016). Artinya, produk harus dibuat dari bahan-bahan yang segar sehingga aman untuk dikonsumsi. Selain itu, variasi menu juga hal yang perlu diperhatikan oleh pengusaha agar konsumen tidak bosan dengan satu jenis menu saja. Pelayanan yang diberikan oleh perusahaan juga akan memengaruhi kepuasan konsumen (Siswanto \& Haryono, 2015). Dalam upaya meningkatkan kepuasan konsumen, pengusaha harus memberikan pelayanan yang baik dengan mengutamakan keramahan, kesopanan, dan kecepatan dalam melayani konsumen. Selain itu, tempat untuk menjual produk juga merupakan hal yang menentukan persepsi kualitas produk oleh konsumen sehingga akan mendorong tercapainya kepuasan konsumen (Greve, 2014). Jadi, pengusaha harus menyediakan tempat yang bersih dan nyaman untuk menjual produknya. Kepuasan yang dirasakan oleh konsumen akan mendorong konsumen untuk mengulang perilaku pembelian (Sudaryono, 2016). Hal ini berarti kepuasan konsumen 
memengaruhi perilaku pembelian ulang konsumen.

Sesuai dengan teori psikologi perkembangan yang menyebutkan bahwa mahasiswa memiliki rentang usia 17 hingga 24 tahun sehingga termasuk dalam kategori remaja akhir dan dewasa awal (Hurlock, 2006). Pada masa tersebut, mahasiswa cenderung berperilaku mudah terpengaruh secara emosional. Kehadiran produk kue artis meningkatkan rasa keingintahuan mahasiswa dan sebagai cara mahasiswa untuk mengikuti arus tren di masyarakat. Hal ini menunjukkan bahwa mahasiswa merupakan salah satu target pasar potensial bagi pengusaha industri kuliner, termasuk pengusaha kue artis. Berdasarkan penjelasan di atas, peneliti ingin mengetahui hubungan antara kepuasan konsumen dan intensi pembelian ulang produk kue artis pada mahasiswa di salah satu universitas di Surakarta.

\section{Metode}

\section{Subjek penelitian}

Dalam melakukan penelitian, peneliti menentukan beberapa karakteristik yang menjadi pedoman dalam pengambilan sampel, yaitu: (a) mahasiswa S1 aktif angkatan 2015 2018 di salah satu universitas di Surakarta, (b) pernah melakukan pembelian pada kue artis di kota Surakarta, dan (c) melakukan pembelian secara langsung di gerai kue artis di kota Surakarta. Penelitian ini dilakukan pada 11 fakultas yang ada di salah satu universitas di
Surakarta. Sampel yang memenuhi kriteria diminta untuk mengisi skala yang sudah disediakan oleh peneliti.

\section{Metode pengumpulan data}

Peneliti melakukan pengumpulan data melalui skala berbentuk Likert. Skala berbentuk Likert dapat digunakan untuk mengukur sikap, pendapat, dan persepsi yang dimiliki individu mengenai suatu fenomena sosial (Sugiyono, 2013). Pada penelitian ini, peneliti menyusun dua skala dengan jumlah 43 butir pernyataan yang disusun sendiri oleh peneliti. Terdapat lima pilihan respon jawaban pada setiap pernyataan, yaitu: Sangat Sesuai (SS), Sesuai (S), Netral (N), Tidak Sesuai (TS), dan Sangat Tidak Sesuai (STS).

Skala pertama adalah skala Intensi Pembelian Ulang. Skala ini disusun untuk mengukur intensi pembelian ulang subjek penelitian. Skala disusun sendiri oleh peneliti dengan mengacu pada aspek-aspek intensi pembelian ulang dari (Hasan, 2013), yaitu: minat transaksional, minat referensial, minat preferensial, dan minat eksploratif. Skala ini terdiri dari 20 butir yang terdiri dari 10 butir favorable dan 10 butir unfavorable.

Skala kedua adalah skala Kepuasan Konsumen. Skala ini disusun untuk mengukur kepuasan konsumen subjek penelitian. Skala disusun sendiri oleh peneliti dengan mengacu pada aspek-aspek kepuasan konsumen dari Zeithaml et al (2013), yaitu: kualitas pelayanan (service quality), kualitas produk (product 
quality), harga (price), faktor-faktor situasional (situational factors), dan faktor-faktor personal (personal factors). Skala ini terdiri dari 36 butir yang terdiri dari 21 butir favorable dan 15 butir unfavorable.

\section{Metode analisis data}

Penelitian ini merupakan penelitian korelasional, yaitu mencari hubungan antara kepuasan konsumen dan intensi pembelian ulang produk kue artis pada mahasiswa. Peneliti menggunakan analisis statistik nonparametrik dengan metode analisis data Kendall's Tau.

\section{Hasil}

\section{Pelaksanaan dan hasil uji coba}

Uji coba dilakukan pada 42 mahasiswa aktif di salah satu universitas di Surakarta angkatan 2015 - 2018, yaitu delapan mahasiswa Fakultas Pertanian dan 34 mahasiswa Fakultas Kedokteran. Penyebaran data uji coba dilakukan secara daring.

Skala Intensi Pembelian Ulang sebelum uji coba berjumlah 20 butir. Setelah dilaksanakan uji coba, terdapat empat butir yang gugur. Koefisien reliabilitas Alpha
Cronbach sebesar .850 dengan rentang indeks daya diskriminasi butir bergerak antara 285 hingga 693.

Skala Kepuasan Konsumen sebelum uji coba berjumlah 36 butir. Setelah dilaksanakan uji coba, ada sembilan butir yang gugur. Koefisien reliabilitas Alpha Cronbach sebesar .883 dengan rentang indeks daya diskriminasi butir bergerak antara .265 hingga .715 .

\section{Pelaksanaan penelitian}

Subjek penelitian ini berjumlah 450 mahasiswa di salah satu universitas di Surakarta yang memenuhi kriteria penelitian. Pengambilan data dilakukan secara luring dan daring. Pengambilan data secara daring dilakukan dengan memberikan skala daring kepada perwakilan mahasiswa setiap angkatan (angkatan 2015 - 2018) pada masing-masing fakultas untuk kemudian disebarkan kepada mahasiswa di angkatannya. Adapun pengambilan data secara luring dilakukan dengan berkunjung ke beberapa fakultas dan meminta secara langsung kepada mahasiswa yang memenuhi kriteria penelitian untuk mengisi skala. Gambaran data penelitian dapat dilihat pada Tabel 2 .

\section{Tabel 2}

Deskripsi Subjek Penelitian

\begin{tabular}{lcc}
\hline \multicolumn{1}{c}{ Keterangan } & $n$ & $\%$ \\
\hline Laki-laki & 84 & 18.67 \\
Perempuan & 366 & 81.33 \\
$N$ & 450 & 100 \\
\hline
\end{tabular}


Pada Tabel 3 dan Tabel 4 telah disajikan deskripsi data penelitian yang menunjukkan tinggi atau rendahnya tingkat kepuasan konsumen dan intensi pembelian ulang.

\section{Tabel 3}

Kategorisasi Variabel Repurchase Intention

\begin{tabular}{lccc}
\hline \multicolumn{1}{c}{ Rentang nilai } & Kategorisasi & $n$ & $\%$ \\
\hline $\mathrm{X}<41$ & Rendah & 66 & 14.7 \\
$41=\mathrm{X}<58$ & Sedang & 312 & 69.3 \\
$\mathrm{X}=58$ & Tinggi & 72 & 16 \\
$N$ & & 450 & 100 \\
\hline
\end{tabular}

\section{Tabel 4}

Kategorisasi Variabel Customer Satisfaction

\begin{tabular}{lccc}
\hline \multicolumn{1}{c}{ Rentang nilai } & Kategorisasi & $n$ & $\%$ \\
\hline $\mathrm{X}<92$ & Rendah & 62 & 13.8 \\
$92=\mathrm{X}<115$ & Sedang & 319 & 70.9 \\
$\mathrm{X}=115$ & Tinggi & 69 & 15.3 \\
$N$ & & 450 & 100 \\
\hline
\end{tabular}

Berdasarkan Tabel 2 dan 3, terlihat bahwa subjek pada penelitian ini memiliki persentase tertinggi pada kategorisasi sedang, baik pada variabel intensi pembelian ulang maupun pada variabel kepuasan konsumen. Pada variabel intensi pembelian ulang, terdapat 312 subjek (69.3\%) yang berada pada kategori sedang. Adapun pada variabel kepuasan konsumen, terdapat 319 subjek (70.9\%) yang berada pada kategori sedang.

\section{Uji hipotesis}

Hipotesis dalam penelitian ini adalah terdapat hubungan antara kepuasan konsumen dan intensi pembelian ulang produk kue artis pada mahasiswa. Semakin tinggi kepuasan konsumen, maka semakin tinggi intensi pembelian ulang. Sebaliknya, semakin rendah kepuasan konsumen, maka semakin rendah pula intensi pembelian ulang. Hasil uji hipotesis dapat dilihat pada Tabel 5 berikut.

\section{Tabel 5}

Hasil Uji Korelasi Kendall's Tau

\begin{tabular}{cccc}
\hline \multicolumn{1}{c}{ Variabel } & $N$ & $\tau$ & $p$ \\
\hline $\begin{array}{l}\text { Kepuasan konsumen*intensi } \\
\text { pembelian ulang }\end{array}$ & 450 & $.405^{* *}$ & .000 \\
\hline
\end{tabular}

Catatan. ${ }^{* *}$ Korelasi signifikan pada taraf 0,01 (2-tailed)

Berdasarkan Tabel 5 di atas, intensi pembelian ulang dengan koefisien diketahui bahwa terdapat korelasi yang korelasi sebesar .405. Hal ini signifikan antara kepuasan konsumen dan menunjukkan bahwa hipotesis pada 
penelitian ini diterima, yaitu terdapat hubungan antara kepuasan konsumen dan intensi pembelian ulang produk kue artis pada mahasiswa di salah satu universitas di Surakarta.

\section{Analisis tambahan}

Selain hasil deskriptif dan uji hipotesis sebagaimana diatas, penelitian ini jugamenghasilkan analisis tambahan berupa uji beda berdasarkan kelamin dan perbedaan merekyang dibeli.

\section{Tabel 6}

Uji Beda Berdasarkan Jenis Kelamin

\begin{tabular}{lcc}
\hline \multicolumn{1}{c}{ Jenis kelamin } & $n$ & $M$ \\
\hline Laki-laki & 84 & 228.98 \\
Perempuan & 366 & 224.70 \\
\hline
\end{tabular}

Berdasarkan Tabel 6 di atas, terlihat bahwa nilai mean ranks kelompok laki-laki lebih tinggi dari nilai mean ranks kelompok perempuan $(228.98>224.70)$. Perbedaan nilai tersebut menunjukkan bahwa intensi pembelian ulang pada subjek laki-laki lebih tinggi dibandingkan intensi pembelian ulang pada subjek perempuan. Untuk mengetahui apakah perbedaan tersebut bermakna atau tidak, peneliti melanjutkan dengan melakukan uji statistik Mann-Whitney U Test seperti terlihat pada Tabel 7 .

\section{Tabel 7}

Hasil Uji Statistik Mann-Whiteney U Test Berdasarkan Jenis Kelamin

\begin{tabular}{lcccc}
\hline Jenis Kelamin & $U$ & $W$ & $Z$ & $A$ \\
\hline $\begin{array}{l}\text { Laki-laki dan } \\
\text { Perempuan }\end{array}$ & 15080.00 & \multirow{2}{*}{82241.00} & -2.72 & .786 \\
\hline
\end{tabular}

Penelitian ini menemukan bahwa tidak terdapat perbedaan yang signifikan antara intensi pembelian ulang subjek perempuan dan subjek laki-laki dengan signifikansi .786 ( $p>$.05). Peneliti selanjutnya juga melakukan uji beda pada merek produk kue artis seperti terlihat pada Tabel 8.

\section{Tabel 8}

Perbedaan Mean Rank Berdasarkan Brand Produk Kue Artis yang Dibeli Subjek

\begin{tabular}{lcc}
\hline \multicolumn{1}{c}{ Merek produk kue artis } & $n$ & $M$ \\
\hline Solo Pluffy & 370 & 218.35 \\
Solo Prabu & 37 & 271.89 \\
Solovely & 9 & 258.39 \\
Vallens Cake & 34 & 244.16 \\
\hline
\end{tabular}


Berdasarkan Tabel 8 di atas, terlihat bahwa nilai mean rank tertinggi diperoleh oleh Solo Prabu, kemudian diikuti oleh Solovely, Vallens Cake, dan Solo Pluffy. Untuk mengetahui apakah perbedaan intensi pembelian ulang subjek penelitian terhadap merek produk kue artis yang ada di kota Surakarta, peneliti menindaklanjuti dengan melakukan uji statistik Kruskal-Wallis.

\section{Tabel 9}

Hasil Uji Statistik Kruskal-Wallis Berdasarkan Brand Produk Kue Artis yang Dibeli Subjek

\begin{tabular}{lccc}
\hline & $\chi^{2}$ & $d f$ & $p$ \\
\hline $\begin{array}{l}\text { Merek Produk Kue } \\
\text { Artis }\end{array}$ & 7.11 & 3 & .068 \\
\hline
\end{tabular}

Berdasarkan Tabel 9 di atas, dapat terlihat bahwa perbedaan nilai signifikansi antara merek produk kue artis di kota Surakarta sebesar .068 ( $p>.05)$. Hal ini menunjukkan bahwa tidak terdapat perbedaan yang signifikan antara intensi pembelian ulang subjek penelitian berdasarkan merek produk kue artis yang dibeli.

\section{Pembahasan}

Hasil uji hipotesis menunjukkan bahwa hipotesis penelitian ini diterima. Artinya terdapat hubungan antara kepuasan konsumen dan intensi pembelian ulang produk kue artis pada mahasiswa di salah satu universitas di Surakarta. Koefisien korelasi yang positif menunjukkan bahwa semakin tinggi kepuasan konsumen, maka semakin tinggi pula intensi pembelian ulang pada produk yang sama. Demikian pula sebaliknya, semakin rendah kepuasan konsumen, maka semakin rendah pula intensi pembelian ulang pada produk yang sama.

Hasil penelitian ini selaras dengan hasil studi yang dilakukan oleh Mensah dan Mensah
(2018) terhadap konsumen dari beberapa restoran di sebuah universitas. Dalam penelitian tersebut dijelaskan bahwa jika restoran memenuhi atau melebihi kepuasan konsumen, maka konsumen akan melakukan intensi pembelian ulang, di mana hal tersebut akan berpengaruh terhadap keuntungan perusahaan.

Kepuasan konsumen menjadi hal yang harus diperhatikan oleh pengusaha karena kepuasan konsumen berdampak pada pembelian yang lebih (Blackwell et al, 2012). Kepuasan konsumen akan memengaruhi apakah konsumen akan membeli produk yang sama lagi atau tidak. Konsumen yang memiliki evaluasi negatif dalam mengonsumsi produk, tidak memiliki kemungkinan untuk membeli produk yang sama. Sementara itu, konsumen yang memiliki evaluasi positif dengan pengalaman konsumsinya akan lebih mungkin untuk membeli kembali produk yang sama. Evaluasi positif konsumen yang muncul ditandai dengan adanya apresiasi konsumen terhadap suatu produk dan pelayanan yang diberikan oleh perusahaan (Araci et al., 2017). 
Konsumen yang memiliki evaluasi positif berarti memiliki pengalaman yang baik sehingga tercapai suatu kepuasan. Jika suatu perusahaan dapat menciptakan konsumen yang puas, maka perilaku-perilaku positif dari konsumen akan meningkat, termasuk intensi pembelian ulang.

Di antara beberapa aspek kepuasan konsumen, peneliti menemukan bahwa aspek kualitas produk $(\beta=.193, t=3.15, p=.002)$, harga $(\beta=.247, t=4.96, p=.000)$, dan faktor personal $(\beta=.320, t=7.63, p=.000)$ merupakan aspek yang paling memengaruhi intensi pembelian ulang pada produk kue artis. Di antara ketiga aspek tersebut, faktor personal, yaitu keadaan emosi konsumen pada saat membeli merupakan faktor yang paling mampu memengaruhi subjek dalam melakukan pembelian berulang pada produk kue artis.

Selama penelitian berlangsung, terdapat keterbatasan dalam melaksanakan penelitian ini. Besarnya populasi dalam penelitian ini mendorong peneliti untuk menyebarkan skala dengan cara daring. Hal ini membuat peneliti memiliki keterbatasan untuk menjelaskan butir yang sulit dipahami oleh subjek penelitian. Selain itu peneliti juga tidak dapat mengawasi secara langsung pengisian skala oleh subjek penelitian.

\section{Simpulan}

Berdasarkan penelitian yang telah dilakukan, dapat disimpulkan bahwa terdapat hubungan positif dan signifikan antara kepuasan konsumen dan intensi pembelian ulang produk kue artis pada mahasiswa di salah satu universitas di Surakarta. Hal ini berarti bahwa semakin tinggi kepuasan konsumen, maka semakin tinggi pula intensi pembelian ulang produk kue artis yang sama. Sebaliknya, semakin rendah kepuasan konsumen, maka semakin rendah pula intensi pembelian ulang produk kue artis yang sama.

\section{Saran}

Pengusaha pada bidang kuliner harus semakin inovatif dan kreatif dalam menjalankan bisnis. Hal ini karena persaingan bisnis pada bidang kuliner semakin ketat. Salah satu hal penting yang harus diperhatikan pengusaha bidang kuliner adalah kepuasan konsumen, agar pelanggan memiliki keinginan untuk melakukan intensi pembelian ulang. Misalnya dengan cara meningkatkan kualitas produk, membuat harga yang terjangkau bagi konsumen, atau memberikan promo yang menarik. Peneliti selanjutnya disarankan untuk mengutamakan pengambilan sampel secara luring agar dapat memfasilitasi jika subjek penelitian mengalami kesulitan dalam memahami butir pernyataan.

\section{Referensi}

Abdullah, T., \& Tantri, F. (2012). Manejemen pemasaran. PT RajaGrafindo Persada.

Alga W. (2019). 3 kue artis di Kota Malang yang cocok untuk oleh-oleh, paling murah Malang Strudel milik Teuku Wisnu Artikel ini telah tayang di Tribunjatim.com dengan judul 3 Kue Artis di Kota Malang yang Cocok untuk Oleh-oleh, Paling 
Murah Malang Strudel Milik Teuku Wi. Tribunnews.Com.

Altintzoglou, T., Heide, M., \& Borch, T. (2016). Food souvenirs: buying behaviour of tourists in Norway. British Food Journal, 118(1), 119-131. https://doi.org/ 10.1108/BFJ-05-2015-0190

Araci, U. E., Bulut, Z. A., \& Kocak, N. (2017). The relation among experiential marketing, customer satisfaction, and behavioral intention: A study an food and beverage businesses. 23rd International Scientific Conference on Economic and Social Development, 361-271.

BEKRAF. (2017). Buku data statistik dan hasil survei ekonomi kreatif. BEKRAF.

Blackwell, R. D., Miniard, P. W., Engel, J. F., Di-ching, P., Yasin, N. M., \& Hood, W. J. (2012). Consumer behavior. Cengage Learning Asia.

Fungai, M. (2017). Factors influencing customer repurchase intention in the fast food industry. A case study of Innscor. Business \& Social Science Journal (BSSJ), 120-141. https:// pdfs.semanticscholar.org/ $12 \mathrm{e} 5 /$ e 29206685 f $27 \mathrm{f} 153$ c 04 e 2 c 50742 d 05 e 5 c 5 e $6 . p d f ?$ ga $=$ 2.19082106.332984768.15909029722010532096.1583108834

Greve, G. (2014). The moderating effects of service and ambience on customer satisfaction in a fast-casual restaurant: A German case study. International Journal of Hospitality and Event Management, 1(1), 147-163. https://doi.org/https:// doi.org/10.1504/IJHEM.2014.066990

Hasan, A. (2013). Marketing dan kasus-kasus pilihan. CAPS (Center for Academic Publishing Service).

Hoyer, W. D., \& Maclnnis, D. J. (2010). Consumer behavior. South-Western.

Hurlock, E. B. (2006). Psikologi perkembangan. Erlangga.

Junaidi, N. W. (2015). Analisa pengaruh customer value terhadap repurchase intention dengan customer satisfaction sebagai variabel intervening di pisa kafe Manyar Surabaya. Jurnal Strategi Pemasaran, 3(1), 1-12.

Kotler, P., \& Keller, K. L. (2012). Marketing management. Pearson Education.

Lunnette, C., \& Andreani, F. (2017). Kepuasan experiential marketing terhadap minat beli ulang di Gyu Kaku Galaxy Mall. Jurnal Hospitality Dan Manajemen Jasa, 5(2), 138-150.

McQuitty, S., Finn, A., \& Wiley, J. B. (2000). Systematically varying consumer satisfaction and its implications for product choice. Academy of Marketing Science Review.

Mensah, I., \& Mensah, R. D. (2018). Effects of service quality and customer satisfaction on repurchase intention in restaurants on University of Cape Coast Campus. Journal of Tourism, Heritage \& Services Marketing, 4(1), 27-36. https://doi.org/ h t tp s : / / n b n - re solving.org / urn:nbn:de:0168-ssoar-66467-7

Nikbin, D., Ismail, I., Marimuthu, M., \& Abu-Jarad, I. Y. (2011). The impact of ûrm reputation on customers' responses to service failure: The role of failure attributions. Business Strategy Series, 19-29.

Pieniak, Z., Verbeke, W., Vanhonacker, F., Guerrero, L., \& Hersleth, M. (2009). Association between traditional food consumption and motives for food choice in six European countries. Appetite, 53(1), 101-108. https:// doi.org/https://doi.org/10.1016/ j.appet2009.05.019

Prastyaningsih, A. S., Suyadi, I., \& Yulianto, E. (2014). Pengaruh customer experience terhadap repurchase intention (Niat membeli ulang) (Survei pada konsumen Kfc di lingkungan warga Rw 3 Desa Kandangrejo, Kedungpring, Lamongan). Jurnal Administrasi Bisnis S1 Universitas Brawijaya, 16(1), 1-8. http:// administrasibisnis.studentjournal.ub.ac.id/ index.php/jab/article/view/669/868 
Rahayu, D., Kumadji, S., \& Kusumawati, A. (2016). Experiental marketing dan pengaruhnya terhadap kepuasan pelanggan dan minat pembelian ulang (Survei pada pelanggan warung Coto Abdullah Daeng Sirua, Kota Makassar). Jurnal Administrasi Bisnis (JAB), 35(2), 197-20. http:// administrasibisnis.studentjournalub.ac.id/ index.php/jab/article/view/1386/1773

Rozekhi, N. A., Hussin, S., Siddiqe, A. S., Rashid, P. D., \& Salmi, N. S. (2016). The influence of food quality on customer satisfaction in fine dining. International Academic Research Journal of Business and Technology, 2(2), 45-50. https:// pdfs.semantics cholar.org/3 ddd / d2c7cef1107baf6ce34d56a9620cd82daf83.pdf? _ga=2.2231282.332984768.15909029722010532096.1583108834

Saeroji, A., \& Wijaya, D. A. (2017). Pemetaan wisata kuliner khas kota Surakarta.Jurnal Pariwisata Terapan, 1(1), 13-27. https:/ /doi.org/https://doi.org/10.22146/ jpt.24968

Setiono, W., Untung, C. Y., \& Jokom, R. (2016). Pengaruh bauran pemasaran jasa terhadap minat beli ulang melalui kepuasan konsumen di depot rawon Malang Mm Surabaya. Jurnal Hospitality Dan Manajemen Jasa, 4(2), 528-539. https://media.neliti.com/media/ publications /84939-ID-pengaruhbauran-pemasaran-jasa-terhadap.pdf

Siswanto, B., \& Haryono, A. T. (2015). The effect of service quality and brand reputation towards customer satisfication and the impact to customer loyality at CV. La Rossa Semarang. Journal of Management, 1(1), 1-11. http:// jurnal.unpand.ac.id/index.php/MS/ article/download/174/170

Sudaryono. (2016). Manajemen pemasaran teori dan implementasi. Penerbit ANDI.

Sugiyono. (2013). Metode penelitian kuantitatif, kualitatif dan R\&D. Alfabeta.

Suhartanto, D., Dean, D., Sosianika, A., \& Suhaeni, T. (2018). Food souvenirs and their influence on tourist satisfaction and behavioral intentions. European Journal of Tourism Research, 18, 133-145. http:/ /ejtr.vumk.eu/index.php/volume18/ 545-v18rp133

Tudoran, A. A., \& Olsen, S. O. (2016). Analyzing the returns of the ûrst transaction satisfaction on intention to purchase and willingness to pay: Evidence for new food products. Journal of Consumer Behaviour, 16(4), 1-15. https://doi.org/ 10.1002/cb.1633

Widjaja, B. T. (2009). Lifestyle marketing. PT. Gramedia Pustaka Utama.

Zeithaml, V. A., Bitner, M. J., \& Gremler, D. D. (2013). Service marketing: Integrating customer focus across the firm. McGrawHill.

Received 29 September 2019

Revised 30 May 2020 Accepted 30 May 2020 